\title{
Nitidine chloride suppresses epithelial-to-mesenchymal transition in osteosarcoma cell migration and invasion through Akt/GSK-3ß/Snail signaling pathway
}

\author{
ZHENXIU CHENG $^{1}$, YINGLONG GUO ${ }^{2}$, YUBAO YANG $^{3}$, JINQING KAN $^{4}$, SHIYOU DAI $^{5}$, \\ MENGFEI HELIAN ${ }^{6}, \mathrm{BO} \mathrm{LI}^{7}$, JIA XU ${ }^{8}$ and CHANGYING LIU ${ }^{9}$
}

\begin{abstract}
${ }^{1}$ Department of Neurosurgery, People's Hospital of Linyi City, Linyi, Shandong; Departments of ${ }^{2}$ Osteology, and
${ }^{3}$ Joint Surgery, Affiliated Hospital of Shandong Medical College, Linyi, Shandong; ${ }^{4}$ Department of Joint Surgery, People's Hospital of Linyi City, Linyi, Shandong; ${ }^{5}$ Department of Osteology, Qingdao Shili Hospital of Eastern Hospital, Qingdao, Shandong; Departments of ${ }^{6}$ Pathology, and ${ }^{7}$ Cardiology, Central Hospital of Zibo, Zibo, Shandong;

${ }^{8}$ Genetic Disease Diagnosis Center, Zibo Maternal and Child Health Hospital, Affiliated to Shandong Academy of Medical Science, Zibo, Shandong; ${ }^{9}$ Department of Osteology, People's Hospital of Linyi City, Linyi, Shandong, P.R. China
\end{abstract}

Received February 10, 2016; Accepted March 20, 2016

DOI: $10.3892 / o r .2016 .4846$

\begin{abstract}
Metastasis is the main cause of death in osteosarcoma. Targeting the process of metastasis is a main strategy for osteosarcoma therapy. As a traditional Chinese medicine, Zanthoxylum nitidum (Roxb) has been applied to treat various diseases, including cancer. However, no evidence has been shown on the anti-metastasis effect of nitidine chloride (NC) that was extracted from Zanthoxylum nitidum (Roxb) on osteosarcoma cells, or its underling mechanisms. In the present study, we aimed to demonstrate the role of $\mathrm{NC}$ on the migration and invasion of osteosarcoma cells. Viability and proliferation of osteosarcoma cells were examined by MTT assay. Then, by appling scratch wound healing assay and Transwell assays, we evaluated migratory and invasive ability of the cells, respectively. Moreover, the expression of epithelial-to-mesenchymal transition (EMT) markers were determined after treatment with NC. Furthermore, the expression of Akt, GSK-3 $\beta$ and Snail were detected by western blot analysis. In addition, the GSK-3 $\beta$ activity was examined by GSK-3 $\beta$ kinase assay. Finally, an inhibitor of GSK-3 $\beta$, lithium chloride $(\mathrm{LiCl})$ was applied to testify the effect of $\mathrm{NC}$ on the expression of EMT markers and Snail. We found that
\end{abstract}

Correspondence to: Dr Changying Liu, Department of Osteology, People's Hospital of Linyi City, No. 27 Jie Fang Road, Linyi, Shandong 276000, P.R. China

E-mail: liuchangyingsubmit@qq.com

Dr Jia Xu, Genetic Disease Diagnosis Center, Zibo Maternal and Child Health Hospital, Affiliated to Shandong Academy of Medical Science, 12 Xing Yuan Dong Road, Zibo, Shandong 255000, P.R. China

E-mail: jiajia88241@sina.com

Key words: nitidine chloride, epithelial-to-mesenchymal transition, invasion, osteosarcoma cells, GSK-3 $\beta$ the proliferative, migratory and invasive ability of the U2OS osteosarcoma cells were all suppressed when treated with NC. $\mathrm{NC}$ increased the expression of E-cadherin and decreased the expression of $\mathrm{N}$-cadherin, vimentin and fibronectin in a dosedependent manner. NC also exerted its ability to suppress the phosphorylation of Akt and GSK-3 $\beta$ so as to activate GSK-3 $\beta$. Then, by using an GSK-3 $\beta$ inhibitor, $\mathrm{LiCl}$, we revealed the effect of GSK-3 $\beta$ in the expression of EMT markers. The expression of Snail was inhibited when treated with $\mathrm{NC}$ and $\mathrm{LiCl}$ also reversed the NC-inhibited Snail expression. Taken together, these results revealed that NC suppressed EMT and decreased the invasive ability of osteosarcoma cells via the Akt/GSK-3 $\beta /$ Snail signaling pathway.

\section{Introduction}

It is well documented that natural products which were extracted from dietary foods or medical plants are reliable sources in chemopreventive or antitumor therapeutic drug pharmaceutical development due to their relatively reduced side-effects (1). Among them, nitidine chloride (NC) (Fig. 1A) is a natural bioactive phytochemical alkaloid which is extracted from the root of Zanthoxylum nitidum (Roxb). Extensive reports have demonstrated that $\mathrm{NC}$ has anti-oxidant, anti-inflammatory, anti-fungal and antiHIV functions $(2,3)$. Recently, studies have focused on its antitumor activity in various types of cancers, such as hepatocellular carcinoma (4), gastric $(5)$, breast $(6,7)$, renal $(8,9)$, nasopharyngeal carcinoma (10) and chronic myeloid leukemia (CML) (11). NC have showed activity for inhibiting proliferation and induces apoptosis of hepatocellular carcinoma, gastric, breast and renal cancer $(4,5,7,8)$. Moreover, $\mathrm{NC}$ was also shown to suppress invasion and metastasis of breast cancer by suppressing c-Src/FAK associated signaling pathway and renal cancer via Akt pathway $(6,9)$. NC has also been demonstrated to be a powerful chemosensitizer for breast cancers (7). Furthermore, a recent study have proved 
A

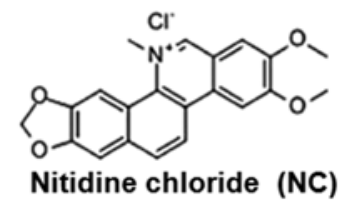

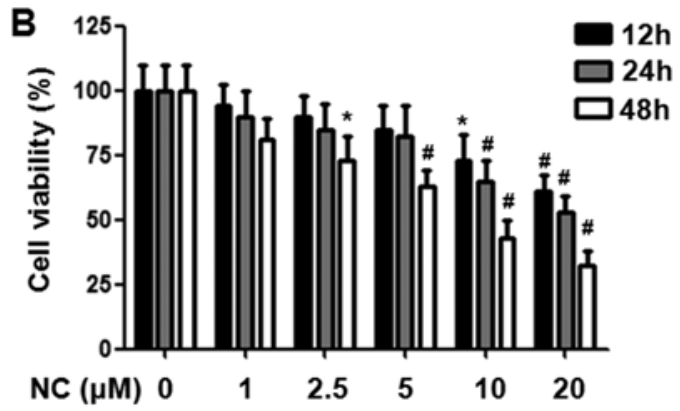

Figure 1. The chemical structure of nitidine chloride (NC) and the effect of $\mathrm{NC}$ on U2OS osteosarcoma cell proliferation. (A) Chemical structure of NC. (B) After treated with NC for different time periods (12, 24 and $48 \mathrm{~h}$ ) at various concentration gradients $(0,1,2.5,5,10$ and $20 \mu \mathrm{M})$, the viability of the U2OS osteosarcoma cells were detected by MTT assay. ${ }^{*} \mathrm{P}<0.05,{ }^{\#} \mathrm{P}<0.01$ vs. the control group. The results represent the mean $\pm \mathrm{SD}$ from three independent experiments.

that $\mathrm{NC}$ can induce erythroid differentiation and apoptosis in CML cells via c-Myc-miRNAs axis (11).

Osteosarcoma is the most common primary bone malignant tumor in young adults and children accounting for approximately $20 \%$ of all primary bone neoplasm (12-14). Nowadays, complete radical surgery is a treatment strategy for local osteosarcoma, but the survival rate is below $20 \%$. When chemotherapy is employed with surgery for improving the prognosis, the survival rate is between 50 and $60 \%$ (15). Due to distal metastases developed prior to diagnosis, osteosarcoma has a poor prognosis. Evidence showed that less than $30 \%$ of patients with osteosarcoma survive for 5 years after lung metastasis (16). The high mortality rate and poor prognosis are attributed to metastasis in osteosarcoma, therefore, it is urgent in osteosarcoma therapy to identify novel drugs to obtain better treatment outcome.

Osteosarcoma cells are highly invasive, so the inhibition of their invasive ability will be effective in its treatment. To gain invasive ability, cancer cells may undergo a unique phenotypic change, epithelial-mesenchymal transition (EMT) which is a morphologic conversion process (17). Characterized by loss of cell adhesion, inhibition of epithelial molecule E-cadherin and gain of mesenchymal markers $\mathrm{N}$-cadherin, vimentin and fibronectin, EMT is considered as a highly conserved cellular process (18). Recent studies have demonstrated EMT in representing mechanisms of carcinoma metastasis $(18,19)$. Among the regulators modulating EMT, Akt and glycogen

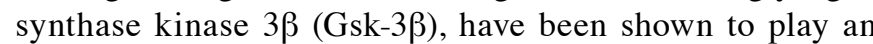
important role in regulating EMT $(20,21)$. Previous reports have documented the crucial role of GSK-3 $\beta$ in regulating cell cytoskeleton maintenance, gene transcription, migration and invasion (22-24). Snail family members, including Snail, Slug, Twist, Zeb1 and SIP1, have been demonstrated to play an crucial role in promoting EMT (25).

The present study was designed to investigate the influence of NC on osteosarcoma cell invasion and EMT, as well as the underlying mechanisms of this effect. To the best of our knowledge, this is the first report to delineate the molecular mechanisms of $\mathrm{NC}$ in the invasion and EMT of osteosarcoma cells.

\section{Materials and methods}

Cell lines and reagents. The U2OS osteosarcoma cell lines were purchased from the American Type Culture Collection (ATCC; Manassas, VA, USA) and were routinely cultured in Dulbecco's modifid Eagle's medium (DMEM; Invitrogen, Carlsbad, CA, USA) containing $10 \%$ fetal bovine serum (FBS; Invitrogen), $100 \mathrm{U} / \mathrm{ml}$ penicillin, and $100 \mu \mathrm{g} / \mathrm{ml}$ streptomycin in $5 \% \mathrm{CO}_{2}$ at $37^{\circ} \mathrm{C}$. Rabbit anti-Akt, phosphor-Akt, rabbit antiGSK-3 $\beta$, phosphor-GSK-3 $\beta$ and rabbit anti-Snail antibodies were purchased from Cell Signaling Technology (Danvers, MA, USA), rabbit anti-E-cadherin, $\mathrm{N}$-cadherin, vimentin and fibronectin antibodies were purchased from Abcam (Cambridge, UK). Alexa-Fluor-488-conjugated and AlexaFluor-594-conjugated goat anti-rabbit IgG were purchased from Invitrogen. Nitidine chloride (NC) was purchased from Shanghai Tauto Biotech Co., Ltd. (Shanghai, China) and then dissolved in dimethyl sulfoxide (DMSO). Lithium chloride $(\mathrm{LiCl})$, a conventional selective inhibitor of GSK-3 $\beta$, was purchased from Sigma-Aldrich (St. Louis, MO, USA).

Cell viability assay. 3-(4,5-Dimethylthiazol-2-yl)-2,5diphenyltetrazolium bromide (MTT) assay was used to detect the cell viability and proliferation. The U2OS osteosarcoma cells $(5,000$ cells/well) in $100 \mu 1$ medium were seeded into 96-well plates. After stimulated with $\mathrm{NC}$ of various doses $(0,1,2.5,5,10$ and $20 \mu \mathrm{M})$, for various time-points $(12,24$ and $48 \mathrm{~h}), 20 \mu 1 \mathrm{MTT}(5 \mathrm{mg} / \mathrm{ml})$ was added into each well. After incubation for $4 \mathrm{~h}, 100 \mu \mathrm{l}$ of DMSO was added to each well for another $15 \mathrm{~min}$. Finally, the absorbance values were determined by microplate reader (Thermo Fisher Scientific, Waltham, MA, USA) at $490 \mathrm{~nm}$.

Western blot analysis. After incubated with NC, the U2OS osteosarcoma cells were collected and lysed. Total cell protein concentrations were detected by using the BCA protein assay kit (Pierce, Rockford, IL, USA). Equal protein from cell lysates were loaded in 12\% SDS-PAGE gels. After electrophoresis, proteins were transferred to PVDF membranes (Millipore, Billerica, MA, USA) and then blocked with 5\% fat-free milk at room temperature for $1 \mathrm{~h}$, and incubated with primary antibodies overnight at $4^{\circ} \mathrm{C}$. Then, the membranes were washed with TBST and incubated with HRP-conjugated secondary antibodies for $1 \mathrm{~h}$ at room temperature. Immune complexes were detected with ECL reagents (Millipore) and the blots were quantified by densitometric analysis using the AlphaImager 2200.

Immunofluorescent staining. After incubated with $\mathrm{NC}$, the U2OS osteosarcoma cells were fixed with $4 \%$ paraformaldehyde, permeabilized with $0.5 \%$ Triton $\mathrm{X}-100$ and then incubated with 5\% normal goat serum for $1 \mathrm{~h}$. Thereafter, the cells were incubated with rabbit anti-E-cadherin and rabbit anti-vimentin overnight at $4^{\circ} \mathrm{C}$. This step was followed by incubation with either Alexa-Fluor-488-conjugated goat anti-rabbit 
IgG or Alexa-Fluor-594-conjugated goat anti-rabbit IgG for $1 \mathrm{~h}$ at room temperature. The cells were further incubated with 4',6-diamidino-2-phenylindole (DAPI)/PBS (1:5,000; Sigma) for $3 \mathrm{~min}$ at room temperature. Finally, images were acquired by using a Nikon Eclipse 80i fluorescence microscope.

Scratch wound healing assay. A scratch wound healing assay was used to examine the migration of the U2OS osteosarcoma cells. Briefly, the U2OS cells $\left(1 \times 10^{6} /\right.$ well) were seeded in 6-well plates cultured with DMEM supplemented with $10 \%$ FBS. When reaching confluency, each well was wounded with a scratch by a $200-\mu 1$ pipette tip. To determine the effect of NC on the migration of $\mathrm{U} 2 \mathrm{OS}$ cells, $5 \mu \mathrm{M} \mathrm{NC}$ was added to each well. After $24 \mathrm{~h}$ of incubation, the wound healing areas were photographed and then the distance between two cell edges were analyzed by ImageJ software.

In vitro invasion assay. To evaluate the effect of $\mathrm{NC}$ on the invasive ability of U2OS osteosarcoma cells, the Transwell system was used. The cells were cultured in Boyden chambers, with $8-\mu \mathrm{m}$ pore filter inserts, in 24 -well plates (Corning Costar, Corning, NY, USA). The pore inserts were pre-coated with Matrigel (BD Biosciences, Franklin Lakes, NJ, USA) overnight. The U2OS cells were pre-treated with $\mathrm{NC}(5 \mu \mathrm{M})$ for $24 \mathrm{~h}$. The U2OS cells $\left(1 \times 10^{5}\right.$ cells/well $)$ were suspended in $100 \mu 1$ DMEM supplemented with $1 \%$ FBS and were added to the upper chamber. DMEM with $10 \%$ FBS and $5 \mu \mathrm{M} \mathrm{NC}$ were added to the lower chamber. After $24 \mathrm{~h}$ of incubation, the cells attaching to the lower surface were fixed with methanol and stained with $0.1 \%$ crystal violet. Five random high-power fields (magnification, x200) of each sample were selected and counted to assess the average number of invasive cells.

GSK-3 $\beta$ kinase assay. A fluorescence peptide substrate-based assay was applied to evaluate GSK-3 $\beta$ kinase activity (Omnia Ser/Thr Recombinant kit; Invitrogen). In brief, GSK-3 $\beta$ complex was prepared from equal amounts of cell lysates by immunoprecipitation, then it was incubated with $10 \mu \mathrm{M}$ of Ser/Thr peptide substrate in kinase reaction buffer (containing $1 \mathrm{mM}$ ATP and $1 \mathrm{mM}$ DTT) for $20 \mathrm{~min}$ at $30^{\circ} \mathrm{C}$. Fluorescence intensity was recorded by measuring the A485 in a 96-well plate. Relative GSK-3 $\beta$ activity was calculated by using untreated cells (equal to 1).

Statistical analysis. The data are expressed as the mean \pm standard deviation (SD). All of the experiments were repeated at least three times. Comparisons among values for all groups were performed by one-way analysis of variance (ANOVA). Holm's t-test was applied for analysis of differences between the different groups. Differences were considered to be statistically significant at $\mathrm{P}<0.05$.

\section{Results}

Suppressive effect of $N C$ on the cell proliferation of osteosarcoma cells. The structure of NC is shown in Fig. 1A. To explore the effect of NC on the proliferation of U2OS osteosarcoma cells, MTT assay was used as described in Materials and methods. As shown in Fig. 1B, different doses $(0,1,2.5$, 5,10 and $20 \mu \mathrm{M}$ ) of $\mathrm{NC}$ were added into the cultured U2OS osteosarcoma cells. After 24-h treatment, NC significantly inhibited the viability of U2OS osteosarcoma cells at a dose beyond $5 \mu \mathrm{M}(10$ and $20 \mu \mathrm{M})$. After 48 -h treatment, NC significantly suppressed proliferation of U2OS osteosarcoma cells at a dose beyond $1 \mu \mathrm{M}(2.5,5,10$ and $20 \mu \mathrm{M})$. However, at doses $<1 \mu \mathrm{M}$, the suppressive effect was not significant. Thus, NC suppressed the proliferation of U2OS osteosarcoma cells time- and dose-dependently. Based on these results, we chose $\mathrm{NC}$ at a dose of $5 \mu \mathrm{M}$ for $24 \mathrm{~h}$ in the following migration and invasion experiments so as to exclude the effect of U2OS osteosarcoma cell proliferation.

Migration and invasion are inhibited by NC in osteosarcoma cells. The wound healing assay was used to examine the role of $\mathrm{NC}$ on the migration of U2OS osteosarcoma cells. The $\mathrm{U} 2 \mathrm{OS}$ osteosarcoma cells were treated with $\mathrm{NC}$ at the dose of $5 \mu \mathrm{M}$ for $24 \mathrm{~h}$. As shown in Fig. 2A, migration of U2OS cells was inhibited by $5 \mu \mathrm{M} \mathrm{NC}$. The results of the wound healing assay indicated that healing over the scratch was significantly reduced when treatment with $\mathrm{NC}$. To further reveal the effect of NC on U2OS osteosarcoma cells invasion, a Transwell assay was applied. The U2OS cells were stimulated with $5 \mu \mathrm{M}$ $\mathrm{NC}$ for $24 \mathrm{~h}$. As shown in Fig. 2B, the invasive ability of U2OS cells were inhibited by $5 \mu \mathrm{M}$ NC. The results of Transwell assay implied that NC could suppress the invasive ability of osteosarcoma cells.

$N C$ alters the expression of EMT markers in osteosarcoma cells. Increasing evidence has demonstrated that EMT played a crucial role in the process of tumour invasion and metastasis $(26,27)$. We thus detected the effect of $\mathrm{NC}$ on the expression of EMT markers (E-cadherin, N-cadherin, vimentin and fibornectin) in the U2OS osteosarcoma cells. Various concentrations of $\mathrm{NC}(0,5$ and $10 \mu \mathrm{M})$ were respectively added to the U2OS cells for $24 \mathrm{~h}$. As shown in Fig. 3A and $\mathrm{B}, \mathrm{NC}$ treatment significantly upregulated the expression of epithelial marker E-cadherin and downregulated the expression of mesenchymal markers $\mathrm{N}$-cadherin, vimentin and fibronectin in the U2OS cells. Immunofluorescent staining was also applied to evaluate the expression of EMT markers. After $\mathrm{NC}(0,5$ and $10 \mu \mathrm{M})$ treatment for $24 \mathrm{~h}$, the cells were stained with E-cadherin and vimentin and analyzed by fluorescence microscopy. As shown in Fig. 3C, 10 and $20 \mu \mathrm{M}$ NC effectively increased the expression of E-cadherin and decreased the expression of vimentin. These results above suggested that NC may alter the expression of EMT markers in a dose-dependent manner. In addition, these results also suggested that the suppressive effect of NC on U2OS cell invasion and migration may be related to EMT.

Akt/GSK-3 $\beta$ pathway is involved in the NC modulated EMT in osteosarcoma cells. Akt is a key regulator of cancer development (28). GSK-3 $\beta$, known to be a survival factor for cancer, plays an important role in various cancer (29-31). Regulation of EMT through Akt/GSK-3 $\beta$ signaling pathway has been demonstrated in tumour progression $(32,33)$. To explore the effect of $\mathrm{NC}$ on Akt and GSK-3 $\beta$ activation, we treated the U2OS cells with various concentrations of $\mathrm{NC}(0,5$ and $10 \mu \mathrm{M}$ ) for $24 \mathrm{~h}$. Then the proteins were extracted, followed by the detection of the phosphorylation of Akt and GSK-3 $\beta$. As 

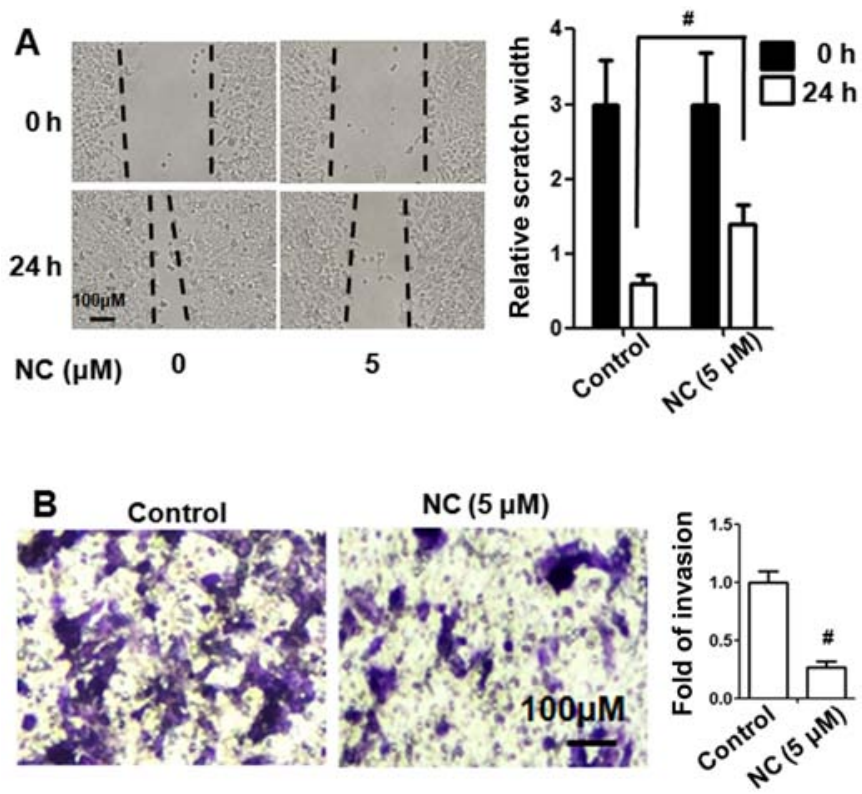

Figure 2. NC inhibits the migration and invasion of U2OS osteosarcoma cells. (A) The U2OS osteosarcoma cells were treated with $\mathrm{NC}$ at the dose of $5 \mu \mathrm{M}$ for $24 \mathrm{~h}$ and then assessed by a wound healing assay. (B) The U2OS osteosarcoma cells were treated with $\mathrm{NC}$ at the dose of $5 \mu \mathrm{M}$ for $24 \mathrm{~h}$. The effect of NC on invasion of U2OS osteosarcoma cells was detected by a Transwell assay. The bar graph represents the results of three independent experiments. ${ }^{~} \mathrm{P}<0.01$ vs. the control group.

shown in Fig. 4A and B, the relative expression of phosphoAkt and phospho-GSK-3 $\beta$ was significantly downregulated dose-dependently. To further verify the result, the effect of NC on GSK-3 $\beta$ activity was examined by GSK-3 $\beta$ kinase assay. The result demonstrated that $\mathrm{NC}$ at various doses $(0$, 5 and $10 \mu \mathrm{M}$ ) can significantly enhance GSK-3 $\beta$ activity in $\mathrm{U} 2 \mathrm{OS}$ cells. To further investigate whether the role of $\mathrm{NC}$ on EMT was attributed to Akt/GSK-3 $\beta$ signaling pathway, $\mathrm{LiCl}$, a GSK-3 $\beta$ inhibitor, was applied to pretreat the U2OS cells for $1 \mathrm{~h}$ before NC to block GSK-3 $\beta$ activation. As shown in Fig. 4D and E, blockade of GSK-3 $\beta$ activity with LiCl could significantly reverse NC-induced E-cadherin, N-cadherin, vimentin and fibronection expression. These above results indicate that $\mathrm{NC}$ could inhibit Akt phosphorylation and then enhanced GSK-3 $\beta$ activity. Furthermore, these results suggested that GSK-3 $\beta$ activation is critical for EMT and Akt/GSK-3 $\beta$ pathway may be involved in NC-inhibited EMT in osteosarcoma cells.

$N C$ induces Snail upregulation via GSK-3 $\beta$ activation in osteosarcoma cells. Evidence has shown that EMT is governed by various regulatory networks. Among them, Snail was the first described transcriptional factor in suppressing E-cadherin expression (34). Thus, we further investigated the effects of $\mathrm{NC}$ on the expression of Snail and the relationship between GSK-3 $\beta$ and Snail. We chose various concentrations of NC $(0,5$ and $10 \mu \mathrm{M})$ to stimulate the U2OS cells for $24 \mathrm{~h}$. As shown in Fig. 5A and B, NC obviously inhibits the expression of Snail with a dose-dependent manner. Then, the U2OS cells were also pretreated with $\mathrm{LiCl}$ for $1 \mathrm{~h}$ before $\mathrm{NC}$ was added. As shown in Fig. 5C and D, pretreatment with the GSK-3 $\beta$ inhibitor LiCl significantly abolished the inhibitory effect of
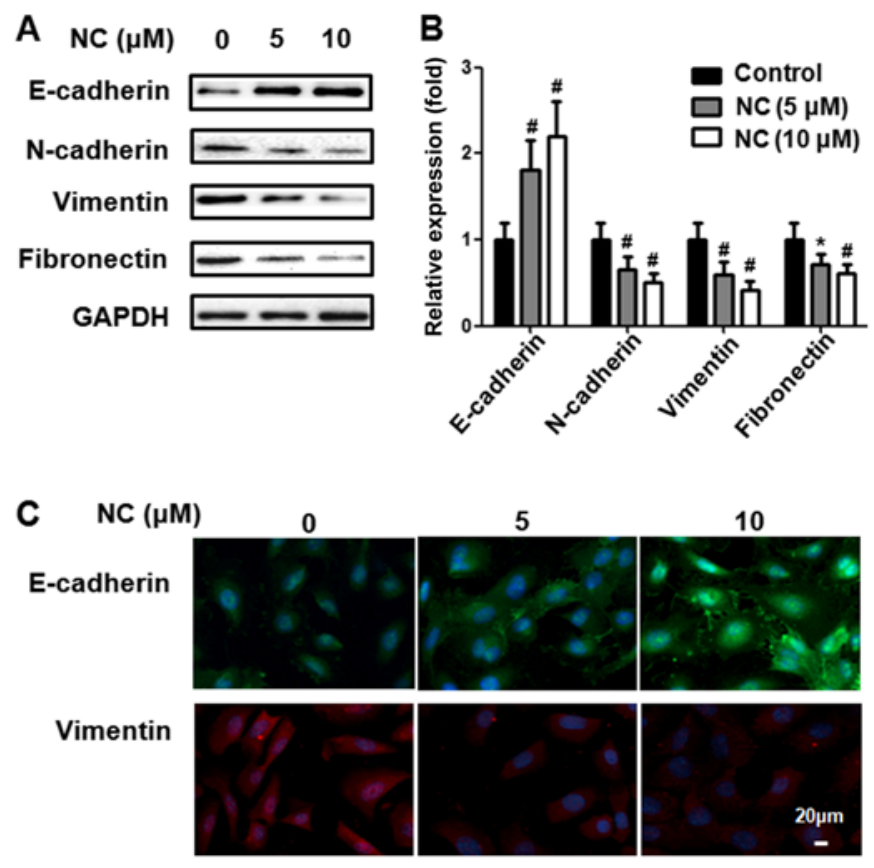

Figure 3. NC increases the expression of E-cadherin and reduces the expression of N-cadherin, vimentin and fibronectin of U2OS osteosarcoma cells. (A) The U2OS osteosarcoma cells were treated with $\mathrm{NC}$ at various concentrations $(0,5$ and $10 \mu \mathrm{M})$ for $24 \mathrm{~h}$ and the level of E-cadherin, N-cadherin, vimentin and fibronectin protein expression were detected by western blot analysis. (B) Statistical analysis of the western blot results. (C) The U2OS osteosarcoma cells were treated with $\mathrm{NC}$ at various concentrations $(0,5$ and $10 \mu \mathrm{M})$ for $24 \mathrm{~h}$ and the expression of $\mathrm{E}$-cadherin and vimentin were detected by immunofluorescent staining. ${ }^{*} \mathrm{P}<0.05,{ }^{\text {"}} \mathrm{P}<0.01$ vs. the control group. Data shown are means \pm SD from three independent experiments.

NC. These results indicate that GSK-3 $\beta$ is a key regulator of Snail and NC inhibits the expression of Snail through blocking the GSK-3 $\beta$ pathway at least in part. Taken together, these results strengthen the opinion that inhibition of metastasis by $\mathrm{NC}$ is regulated by suppression of EMT through Akt/GSK-3 $\beta$ / Snail signaling pathway in osteosarcoma cells.

\section{Discussion}

Metastasis is regarded as a leading cause of mortality of most cancer patients. Exploration on the molecular mechanisms of metastasis is a crucial issue in cancer research. Thus, it is very important to seek effective drugs to suppress the metastasis of cancer. Recently, increased attention was paid on natural products in tumor therapy for their anticancer property and less severe side-effects $(35,36)$. As a kind of bioactive phytochemical alkaloid extracted from Zanthoxylum nitidum (Roxb), $\mathrm{NC}$ has been well documented to have the ability to induce apoptosis and inhibit the proliferation, migration and invasion of hepatocellular carcinoma, gastric, breast, renal cancer cells and CML cells $(4-9,11)$. Although previous studies reported the antitumor effect of $\mathrm{NC}$, the role of $\mathrm{NC}$ on osteosarcoma cell migration and invasion have not been clearly elucidated, or EMT and its detailed molecular mechanisms. Our study first examined the effect of $\mathrm{NC}$ on the viability of osteosarcoma cells. We found that $5 \mu \mathrm{M} \mathrm{NC}$ could significantly inhibit cell proliferation after $48 \mathrm{~h}$ of treatment, while there was no significant effect before $24 \mathrm{~h}$. Thus, we selected $24 \mathrm{~h}$ as the 
A

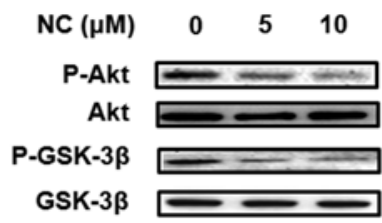

B

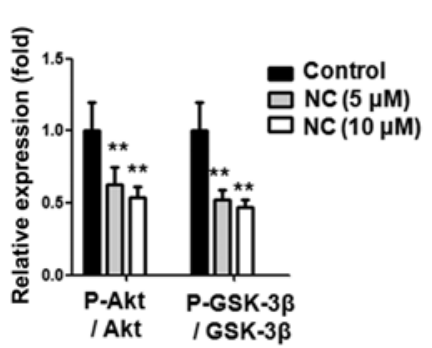

C

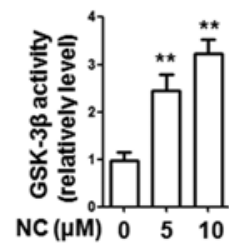

D

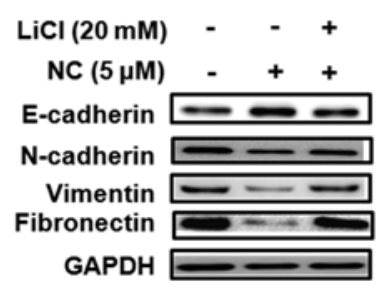

E

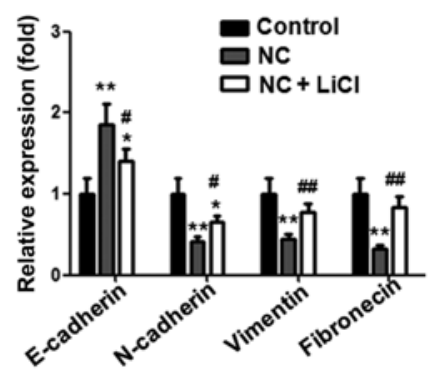

Figure 4. GSK-3 $\beta$ regulates the NC-mediated epithelial-to-mesenchyma transition (EMT) in U2OS osteosarcoma cells. (A) The U2OS osteosarcoma cells were stimulated with $\mathrm{NC}$ at various concentrations $(0,5$ and $10 \mu \mathrm{M})$ for $24 \mathrm{~h}$, expression of $\mathrm{p}-\mathrm{Akt}$ and $\mathrm{p}-\mathrm{GSK}-3 \beta$ were analyzed by western blotting. (B) Statistical analysis of the western blotting results. (C) The U2OS osteosarcoma cells were stimulated with $\mathrm{NC}$ at various concentrations $(0,5$ and $10 \mu \mathrm{M})$ for $24 \mathrm{~h}$, GSK-3 $\beta$ activity was determined by GSK-3 $\beta$ kinase assay. (D) The U2OS osteosarcoma cells were treated with $\mathrm{NC}(5 \mu \mathrm{M})$ and/or LiC $(20 \mathrm{mM})$ for $24 \mathrm{~h}$, then expression of E-cadherin, N-cadherin, vimentin and fibronectin were assessed by western blotting assay. (E) Statistical analysis of the western blotting results. ${ }^{*} \mathrm{P}<0.05,{ }^{* * *} \mathrm{P}<0.01$ vs. the control group. ${ }^{\#} \mathrm{P}<0.05,{ }^{\# \#} \mathrm{P}<0.01$, compared with the cells treated with NC. Data shown are means \pm SD from three independent experiments.

stimulation time-point and $5 \mu \mathrm{M}$ as the stimulation dose in the following migration and invasion experiments, so that the influence of proliferation was excluded. For the first time, the present study demonstrated that NC could effectively inhibit the migration and invasion of osteosarcoma cells by using wound healing and Transwell assays. These results revealed the anti-metastatic activity of NC.

The metastasis of osteosarcoma is a complex process which includes cell migration, invasion, and adhesion (37). EMT is a special phenotypic transformation by which epithelial cells lose the polarity and cell-cell adhesion, then obtain the migratory and invasive properties of mesenchymal cells. EMT is characterized by downregulated epithelial marker E-cadherin and upregulated mesenchymal markers $\mathrm{N}$-cadherin, vimentin and fibronectin. Cancer cells can gain the capacity to invade adjacent tissues, break through the basement membrane, and finally enter the bloodstream when acquiring the mesenchymal phenotype through EMT (38). Several studies have reported the role of EMT in osteosarcoma metastasis, thus implying the poor prognosis of
A

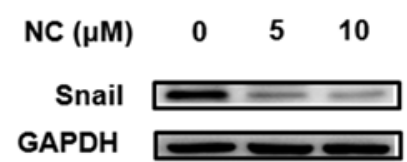

C

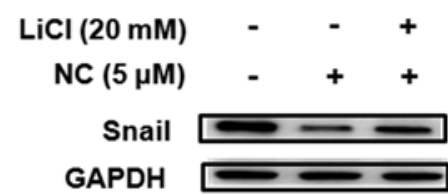

Figure 5. GSK-3 $\beta$ mediates the expression of Snail in NC-treated U2OS osteosarcoma cells. (A) The U2OS osteosarcoma cells were stimulated with $\mathrm{NC}$ at various concentrations $(0,5$ and $10 \mu \mathrm{M})$ for $24 \mathrm{~h}$, expression of Snail were analyzed by western blotting. (B) Statistical analysis of the western blot results. (C) The U2OS osteosarcoma cells were treated with NC (5 $\mu \mathrm{M})$ and/or $\mathrm{LiCl}(20 \mathrm{mM})$ for $24 \mathrm{~h}$, then expression of Snail were assessed by western blotting assay. (D) Statistical analysis of the western blot results. ${ }^{*} \mathrm{P}<0.05,{ }^{* *} \mathrm{P}<0.01$ vs. the control group. ${ }^{\#} \mathrm{P}<0.05,{ }^{\# \#} \mathrm{P}<0.01$, compared with the cells treated with NC. Data shown are means \pm SD from three independent experiments

osteosarcoma $(39,40)$. In this study, we explored the role of NC on EMT in osteosarcoma cells. The present study showed that NC increased the expression of the epithelial marker E-cadherin and decreased the expression of mesenchymal markers $\mathrm{N}$-cadherin, vimentin and fibronectin with a dosedependent manner. Our results demonstrated that NC inhibited EMT in osteosarcoma cells.

The Akt/GSK-3 $\beta$ signaling pathway has been documented to regulate various cell functions, such as proliferation, apoptosis and angiogenesis (41-43). Expression of Akt/GSK-3 $\beta$ is associated with cell proliferation, apoptosis and angiogenesis $(24,41-43)$. Notably, GSK-3 $\beta$ activity is regulated by a site-specific phosphorylation of Tyr216/Ser9 residues, the phosphorylation of GSK-3 $\beta$ resulted in its inactivation (44). Moreover, Akt/GSK-3 $\beta$ regulates the stability and transcription of Snail in some cancer cells and the inactivation of GSK-3 $\beta$ is crucial to induce Snail expression $(32,45)$. Previous studies documented the role of Akt/GSK-3 $\beta /$ Snail in regulating the metastasis of various type of tumours via modulating EMT, such as colorectal, gastric, hepatocellular carcinoma, prostate, lung, breast, head and neck squamous cell carcinoma and bladder cancer $(21,32,33,45-49)$. In the present study, the Akt/GSK-3 $\beta$ activity in osteosarcoma cells was examined by western blot analysis and GSK-3 $\beta$ kinase assay. We found that expression of phosphor-Akt and phosphor-GSK-3 $\beta$ was decreased while GSK-3 $\beta$ activity was increased when treated with NC. To confirm that the GSK-3 $\beta$ signaling pathway was involved in NC-inhibited EMT in osteosarcoma cells, we blocked GSK-3 $\beta$ activity by appling $\mathrm{LiCl}$, the GSK-3 $\beta$ inhibitor. The present study showed that suppression of GSK-3 $\beta$ activity by $\mathrm{LiCl}$ significantly reversed NC-induced E-cadherin, $\mathrm{N}$-cadherin, vimentin and fibro- 
nectin expression. These results further demonstrated that GSK-3 $\beta$ activation is essential for EMT and the effect of NC might be GSK-3 $\beta$-dependent.

Finally, we explored the role of NC and GSK-3 $\beta$ on transcription factor Snail. Snail, a zinc finger protein, is one of the most crucial members in Snail superfamily. Previous studies have demonstrated its role in modulating EMT through downregulate the expression of epithelial marker E-cadherin and upregulate of mesenchymal markers $\mathrm{N}$-cadherin, vimentin and fibronectin by binding with some boxes in the promotor region (50). Snail is involved in several types of cancer progression and metastasis via regulating EMT $(33,47,50)$. The stability and transcription of Snail may be modulated by GSK-3 $\beta$ (32). In the present study, we found that the expression of Snail was decreased when treated with NC in a dose-dependent manner. While $\mathrm{LiCl}$ significantly reversed the effect further indicating that GSK-3 $\beta$ was upstream of Snail. The above results demonstrated that NC inhibited the expression of Snail via the GSK-3 $\beta$ pathway.

In summary, this study for the first time indicate that NC inhibited the migration and invasion of osteosarcoma cells by suppressing EMT. Moreover, the inhibitory role of NC in EMT was regulated via the Akt/GSK-3 $/$ /Snail pathway. Taken together, NC suppresses the invasive ability of osteosarcoma cells by inhibiting EMT through the Akt/GSK-3 $\beta$ / Snail signaling pathway. Thus, our finding suggested that NC is a promising agent in osteosarcoma therapy. Further in vivo research should be performed.

\section{Acknowledgements}

The present study was supported by the Science Foundation of Shandong Province (no. ZR2014HP005).

\section{References}

1. Gordaliza M: Natural products as leads to anticancer drugs. Clinical \& Translational Oncology: Official Publication of the Federation of Spanish Oncology Societies and of the National Cancer Institute of Mexico 9: 767-776, 2007.

2. Wang Z, Jiang W, Zhang Z, Qian M and Du B: Nitidine chloride inhibits LPS-induced inflammatory cytokines production via MAPK and NF-kappaB pathway in RAW 264.7 cells. J Ethnopharmacol 144: 145-150, 2012.

3. Del Poeta M, Chen SF, Von Hoff D, Dykstra CC, Wani MC, Manikumar G, Heitman J, Wall ME and Perfect JR: Comparison of in vitro activities of camptothecin and nitidine derivatives against fungal and cancer cells. Antimicrob Agents Chemother 43: 2862-2868, 1999.

4. Liao J, Xu T, Zheng JX, Lin JM, Cai QY, Yu DB and Peng J: Nitidine chloride inhibits hepatocellular carcinoma cell growth in vivo through the suppression of the JAK1/STAT3 signaling pathway. Int J Mol Med 32: 79-84, 2013.

5. Chen J, Wang J, Lin L, He L, Wu Y, Zhang L, Yi Z, Chen Y, Pang X and Liu M: Inhibition of STAT3 signaling pathway by nitidine chloride suppressed the angiogenesis and growth of human gastric cancer. Mol Cancer Ther 11: 277-287, 2012.

6. Pan X, Han H, Wang L, Yang L, Li R, Li Z, Liu J, Zhao Q, Qian M, Liu M, et al: Nitidine chloride inhibits breast cancer cells migration and invasion by suppressing c-Src/FAK associated signaling pathway. Cancer Lett 313: 181-191, 2011.

7. Sun M, Zhang N, Wang X, Cai C, Cun J, Li Y, Lv S and Yang Q: Nitidine chloride induces apoptosis, cell cycle arrest, and synergistic cytotoxicity with doxorubicin in breast cancer cells Tumour Biol 35: 10201-10212, 2014.

8. Fang Z, Tang Y, Jiao W, Xing Z, Guo Z, Wang W, Xu Z and Liu Z: Nitidine chloride induces apoptosis and inhibits tumor cell proliferation via suppressing ERK signaling pathway in renal cancer. Food Chem Toxicol 66: 210-216, 2014.
9. Fang Z, Tang Y, Jiao W, Xing Z, Guo Z, Wang W, Shi B, Xu Z and Liu Z: Nitidine chloride inhibits renal cancer cell metastasis via suppressing AKT signaling pathway. Food Chem Toxicol 60: 246-251, 2013.

10. Kang M, Ou H, Wang R, Liu W and Tang A: The effect of nitidine chloride on the proliferation and apoptosis of nasopharyngeal carcinoma cells. J BUON 19: 130-136, 2014.

11. Liu N, Li P, Zang S, Liu Q, Ma D, Sun X and Ji C: Novel agent nitidine chloride induces erythroid differentiation and apoptosis in CML cells through c-Myc-miRNAs axis. PLoS One 10: e0116880, 2015.

12. Ottaviani G and Jaffe N: The epidemiology of osteosarcoma. Cancer Treat Res 152: 3-13, 2009.

13. Mirabello L, Troisi RJ and Savage SA: Osteosarcoma incidence and survival rates from 1973 to 2004: Data from the Surveillance, Epidemiology, and End Results Program. Cancer 115: 1531-1543, 2009.

14. Huh WW, Holsinger FC, Levy A, Palla FS and Anderson PM: Osteosarcoma of the jaw in children and young adults. Head Neck 34: 981-984, 2012.

15. Gaffney R, Unni KK, Sim FH, Slezak JM, Esther RJ and Bolander ME: Follow-up study of long-term survivors of osteosarcoma in the prechemotherapy era. Hum Pathol 37: 1009-1014, 2006.

16. Mohseny AB, Machado I, Cai Y, Schaefer KL, Serra M, Hogendoorn PC, Llombart-Bosch A and Cleton-Jansen AM: Functional characterization of osteosarcoma cell lines provides representative models to study the human disease. Lab Invest 91: 1195-1205, 2011

17. Vuoriluoto K, Haugen H, Kiviluoto S, Mpindi JP, Nevo J, Gjerdrum C, Tiron C, Lorens JB and Ivaska J: Vimentin regulates EMT induction by Slug and oncogenic H-Ras and migration by governing Axl expression in breast cancer. Oncogene 30: 1436-1448, 2011.

18. Rosanò L, Cianfrocca R, Spinella F, Di Castro V, Nicotra MR, Lucidi A, Ferrandina G, Natali PG and Bagnato A: Acquisition of chemoresistance and EMT phenotype is linked with activation of the endothelin A receptor pathway in ovarian carcinoma cells. Clin Cancer Res 17: 2350-2360, 2011.

19. Elloul S, Vaksman O, Stavnes HT, Trope CG, Davidson B and Reich R: Mesenchymal-to-epithelial transition determinants as characteristics of ovarian carcinoma effusions. Clin Exp Metastasis 27: 161-172, 2010.

20. Liu J, Gao L, Zhang H, Wang D, Wang M, Zhu J, Pang C and Wang C: Succinate dehydrogenase 5 (SDH5) regulates glycogen synthase kinase $3 \beta-\beta$-catenin-mediated lung cancer metastasis. J Biol Chem 288: 29965-29973, 2013.

21. Zhou SL, Zhou ZJ, Hu ZQ, Li X, Huang XW, Wang Z, Fan J, Dai $Z$ and Zhou J: CXCR2/CXCL5 axis contributes to epithelialmesenchymal transition of HCC cells through activating PI3K/ Akt/GSK-3 $3 /$ Snail signaling. Cancer Lett 358: 124-135, 2015.

22. Yoshimura T, Kawano Y, Arimura N, Kawabata S, Kikuchi A and Kaibuchi K: GSK-3beta regulates phosphorylation of CRMP-2 and neuronal polarity. Cell 120: 137-149, 2005.

23. Liu C, Li Y, Semenov M, Han C, Baeg GH, Tan Y, Zhang Z, Lin $\mathrm{X}$ and He X: Control of beta-catenin phosphorylation/degradation by a dual-kinase mechanism. Cell 108: 837-847, 2002.

24. Zhang X, Chen T, Zhang J, Mao Q, Li S, Xiong W, Qiu Y, Xie Q and Ge J: Notch1 promotes glioma cell migration and invasion by stimulating $\beta$-catenin and NF- $\kappa$ B signaling via AKT activation. Cancer Sci 103: 181-190, 2012.

25. Yuan H, Kajiyama H, Ito S, Yoshikawa N, Hyodo T, Asano E, Hasegawa $\mathrm{H}$, Maeda M, Shibata K, Hamaguchi M, et al: ALX1 induces snail expression to promote epithelial-to-mesenchymal transition and invasion of ovarian cancer cells. Cancer Res 73: 1581-1590, 2013.

26. Mitra A, Mishra L and Li S: EMT, CTCs and CSCs in tumor relapse and drug-resistance. Oncotarget 6: 10697-10711, 2015.

27. Qureshi R, Arora H and Rizvi MA: EMT in cervical cancer: Its role in tumour progression and response to therapy. Cancer Lett 356: 321-331, 2015.

28. Somanath PR, Vijai J, Kichina JV, Byzova T and Kandel ES: The role of PAK-1 in activation of MAP kinase cascade and oncogenic transformation by Akt. Oncogene 28: 2365-2369, 2009.

29. de Araújo WM, Vidal FC, de Souza WF, de Freitas JC Jr, de Souza W and Morgado-Diaz JA: PI3K/Akt and GSK-3 $\beta$ prevents in a differential fashion the malignant phenotype of colorectal cancer cells. J Cancer Res Clin Oncol 136: 1773-1782, 2010. 
30. Zhang B, Yang Y, Shi X, Liao W, Chen M, Cheng AS, Yan H, Fang C, Zhang S, Xu G, et al: Proton pump inhibitor pantoprazole abrogates adriamycin-resistant gastric cancer cell invasiveness via suppression of Akt/GSK- $\beta / \beta$-catenin signaling and epithelialmesenchymal transition. Cancer Lett 356: 704-712, 2015.

31. Chen J, Chan AW, To KF, Chen W, Zhang Z, Ren J, Song C, Cheung YS, Lai PB, Cheng SH, et al: SIRT2 overexpression in hepatocellular carcinoma mediates epithelial to mesenchymal transition by protein kinase B/glycogen synthase kinase-3// $\beta$ catenin signaling. Hepatology 57: 2287-2298, 2013.

32. Liu ZC, Wang HS, Zhang G, Liu H, Chen XH, Zhang F, Chen DY, Cai SH and Du J: AKT/GSK-3 $\beta$ regulates stability and transcription of snail which is crucial for bFGF-induced epithelial-mesenchymal transition of prostate cancer cells. Biochim Biophys Acta 1840: 3096-3105, 2014.

33. Liu CW, Li CH, Peng YJ, Cheng YW, Chen HW, Liao PL, Kang JJ and Yeng MH: Snail regulates Nanog status during the epithelial-mesenchymal transition via the Smad1/Akt/GSK3 $\beta$ signaling pathway in non-small-cell lung cancer. Oncotarget 5 : 3880-3894, 2014.

34. Lu ZY, Dong R, Li D, Li WB, Xu FQ, Geng Y and Zhang YS: SNAI1 overexpression induces stemness and promotes ovarian cancer cell invasion and metastasis. Oncol Rep 27: 1587-1591, 2012.

35. Surh YJ: Cancer chemoprevention with dietary phytochemicals. Nat Rev Cancer 3: 768-780, 2003

36. Thomasset SC, Berry DP, Garcea G, Marczylo T, Steward WP and Gescher AJ: Dietary polyphenolic phytochemicals - promising cancer chemopreventive agents in humans? A review of their clinical properties. Int J Cancer 120: 451-458, 2007.

37. Weng CJ and Yen GC: Chemopreventive effects of dietary phytochemicals against cancer invasion and metastasis: Phenolic acids, monophenol, polyphenol, and their derivatives. Cancer Treat Rev 38: 76-87, 2012.

38. Turley EA, Veiseh M, Radisky DC and Bissell MJ: Mechanisms of disease: Epithelial-mesenchymal transition - does cellular plasticity fuel neoplastic progression? Nat Clin Pract Oncol 5: 280-290, 2008

39. Hou CH, Lin FL, Hou SM and Liu JF: Cyr61 promotes epithelialmesenchymal transition and tumor metastasis of osteosarcoma by Raf-1/MEK/ERK/Elk-1/TWIST-1 signaling pathway. Mol Cancer 13: 236, 2014.

40. Guo X, Zhang J, Pang J, He S, Li G, Chong Y, Li C, Jiao Z, Zhang S and Shao M: MicroRNA-503 represses epithelial-mesenchymal transition and inhibits metastasis of osteosarcoma by targeting c-myb. Tumour Biol: Jan 14, 2016 (Epub ahead of print).
41. Zhang X, Jiang D, Jiang W, Zhao M and Gan J: Role of TLR4mediated PI3K/AKT/GSK-3 $\beta$ signaling pathway in apoptosis of rat hepatocytes. Biomed Res Int 2015: 631326, 2015.

42. Lin L, Chen YS, Yao YD, Chen JQ, Chen JN, Huang SY, Zeng YJ, Yao HR, Zeng SH, Fu YS, et al: CCL18 from tumor-associated macrophages promotes angiogenesis in breast cancer. Oncotarget 6: 34758-34773, 2015.

43. Liao K, Li J and Wang Z: Dihydroartemisinin inhibits cell proliferation via AKT/GSK3 $\beta /$ cyclinD1 pathway and induces apoptosis in A549 lung cancer cells. Int J Clin Exp Pathol 7: 8684-8691, 2014.

44. Doble BW and Woodgett JR: GSK-3: Tricks of the trade for a multi-tasking kinase. J Cell Sci 116: 1175-1186, 2003.

45. Ngo HK, Lee HG, Piao JY, Zhong X, Lee HN, Han HJ, Kim W, $\mathrm{Kim} \mathrm{DH}$, Cha YN, Na HK, et al: Helicobacter pylori induces Snail expression through ROS-mediated activation of Erk and inactivation of GSK-3 $\beta$ in human gastric cancer cells. Mol Carcinog: Jan 25, 2016 (Epub ahead of print). doi: 10.1002/ mc.22464.

46. Zhang B, Yin C, Li H, Shi L, Liu N, Sun Y, Lu S, Liu Y, Sun L, Li X, et al: Nirl promotes invasion of breast cancer cells by binding to chemokine (C-C motif) ligand 18 through the PI3K/Akt/GSK3 $3 /$ Snail signalling pathway. Eur J Cancer 49: 3900-3913, 2013

47. Zhang J, Wei J, Lu J, Tong Z, Liao B, Yu B, Zheng F, Huang X, Chen Z, Fang Y, et al: Overexpression of Rab25 contributes to metastasis of bladder cancer through induction of epithelialmesenchymal transition and activation of Akt/GSK-3 $\beta /$ Snail signaling. Carcinogenesis 34: 2401-2408, 2013.

48. Wang H, Wang HS, Zhou BH, Li CL, Zhang F, Wang XF, Zhang G, Bu XZ, Cai SH and Du J: Epithelial-mesenchymal transition (EMT) induced by TNF- $\alpha$ requires AKT/GSK-3 $\beta$ mediated stabilization of snail in colorectal cancer. PLoS One 8: e56664, 2013

49. Maseki S, Ijichi K, Tanaka H, Fujii M, Hasegawa Y, Ogawa T, Murakami S, Kondo E and Nakanishi H: Acquisition of EMT phenotype in the gefitinib-resistant cells of a head and neck squamous cell carcinoma cell line through Akt/GSK-3 $\beta /$ snail signalling pathway. Br J Cancer 106: 1196-1204, 2012.

50. Cano A, Pérez-Moreno MA, Rodrigo I, Locascio A, Blanco MJ, del Barrio MG, Portillo F and Nieto MA: The transcription factor snail controls epithelial-mesenchymal transitions by repressing E-cadherin expression. Nat Cell Biol 2: 76-83, 2000. 